\title{
Quantum crystallography: past, present and future
}

\section{Dylan Jayatilaka}

\author{
School of Molecular Sciences, The University of Western Australia, 35 Stirling Highway, Crawley 6009, Perth,Western Australia \\ dylan.jayatilaka@uwa.edu.au
}

What is quantum crystallography? [1]

Is it a hyped-up fad?

Is it "theory" or "experiment"?

What can it do? Is it useful?

Why has it become a new (perhaps better: reborn) IUCr

commision?

\section{The past}

At the 2002 IUCr meeting in Geneva (rescheduled from Jerusalem) I was asked to speak after Jerome Karle, Nobel Laureate and one of those who had coined the term quantum crystallography (QCr) [2]. The room was packed, and soon there was a (second order?) phase change in the audience: either asleep or fidgeting. When Karle finished there was an immediate and astounding rush of people to leave. It was a bit disheartening for me; I had to shout over the commotion. Then there was more chaos, as some even turned back. I like to think it was because of me, but more likely it was defeat. I will review some of this 2002 material and show that $\mathrm{QCr}$ was in fact born with quantum mechanics itself [3]. I want to also highlight the work of Tibor Koritsanszky, recently lost to us, who together with Ewald medallist Philip Coppens brought about the "golden age" of our field [4].

\section{The present}

In a recent Australian Research Council grant application of mine assessor B lamented: "QCr is slowly creeping into crystallographic refinement to provide a better treatment of light i.e. hydrogen atoms ... but how useful will it be in the vast majority of structural refinements?". Even assessor D found it "hard to get excited about hydrogen atoms (sorry)". Perhaps D is a physicist: only a nonchemist could be so callously unmoved by the proton, which forms the skin of all molecules, and is the fat positive partner of the beauteous electron! Surely these two are the hands of chemistry itself?! But I am actually rather pleased by that creeping comment: to me, it evokes a kind of desease-like inevitability: it resonates with the lack of direct funding [5]. In any case, I will explain why QCr is hard work, and I will review the impressive current progress by several groups.

\section{The future}

I think, except for Arthur C. Clarke, there have been no futorologist of note. Nevertheless, I will attempt to describe my vision for the use of model "experimental" wavefunctions to encode much more than just structral information; how QCr, the synthesis of quantum chemistry and crystallography will produce high quality databases worth mining; and how QCr has much to offer cognate fields like single-molecule and electron "diffraction". 
[1] (a) Jayatilaka, D., N. C. (2012). Modern Charge-Density Analysis, edited by C. Gatti \& P. Macchi, pp. 213-257. Springer. (b) Grabowsky, S., Genoni, A., Buergi, H.-B. (2017). Chem. Sci. 8, 4159; (c) Genoni, A.., et. al. (2018). Chem. Eur. J. 24, 10881.

[2] Massa, L., Huang, L., Karle, J. (1995). Int. J. Quantum Chem. 56, 371.

[3] James, R.W., Waller, I., Hartree, D.R. (1928) Proc. Royal Soc. London Ser. A 118, 334

[4] Koritsanszky, T.S., Coppens, P. (2001). Chem. Rev. 101, 1583

[5] Take heart east-coast scientists! Research can continue, even in Western Australia where, to paraphrase W. Pauli and P. Doherty, we are not even of the Pacific bogan variety, https://tinyurl.com/jmv6uyne .

Keywords: Quantum Crystallography, QCr, Hirshfeld Atom Refinement, HAR 